\title{
A Theoretical Approach to Management of Examination Phobia among High School Students
}

Sindhu $\mathrm{P}^{1}$

\section{ABSTRACT}

This paper focuses on exam phobia among students. Exam phobia is an irrational fear that leads to avoidance of the feared situation or object which in turn increases the severity of the phobia. Exam phobia refers to the excessive worry about upcoming exams, Lifestyle issues, Negative thinking, self criticism, studying styles, psychological factors, fear of being evaluated, apprehension about the consequences, and is experienced by many normal students. It affects socially and leads to social withdrawal, avoidance of friends and family, self defeating thought, suicidal thoughts, etc. Therefore the management of Examination Phobia has become an essential research topic. The main objective of this paper is to introduce interventions for the Management of Examination Phobia and to assess the results of the same among High School Students using Cognitive Behavioural Therapy (CBT), Progressive Muscular Relaxation Technique, Benson's Relaxation Response, Guided Imagery and Recommendations for administrators, teachers, parents, school counsellors and students themselves.

Keywords: Anxiety, Depression, Phobia, Stress, Students.

Exam Phobia is a psychological condition in which people experience extreme stress, anxiety, discomfort and irrational fear during or before examination. A little nervousness or tension is healthy for you that it can help you perform your best. But when this tension or stress becomes so excessive that it actually hampers your performance on an exam and then it is called Exam Phobia or Test Anxiety.

Everybody experiences fear or anxiety in life, but the threshold differs from individual to individual. When the fear or anxiety is strong and irrational this can be considered as phobia. Stimulus that causes phobia differs from individual to individual.

${ }^{1}$ Department of Psychology, Bharathiar University, Coimbatore 


\section{A Theoretical Approach to Management of Examination Phobia among High School Students}

\section{Causes of Exam Phobia:}

1. Unrealistic expectations of parents from their children.

2. Parental pressure that cause greater worry and fear of failure.

3. Excessive pressure and fear of teachers.

4. Inadequate study.

5. Obsessive Compulsive Disorder.

6. Poor motivation and lack of self esteem.

7. Poor nutrition and sleeping disturbance.

Examination phobia has Cognitive, Emotional and Physiological components. Cognitive components include: thinking of failure, worrying about possible outcomes, lack of confidence, Feeling of excessive mental pressure, Suicidal ideation, Negative self talk, etc. Emotional components include: Tension, Apprehension, Nervousness, Depression, Frustration, etc. Physiological components include: Nausea, Palpitation, Perspiration, Trembling and limbs become cold, etc. All these together leads to poor performance, then to poor achievement, which in turn creates anxiety. They may be preoccupied with negative thoughts, doubting their academic ability and intellectual competence (Sarason \& Sarason, 1990).

\section{The present study proposes to have the following objectives:-}

1. To assess the level of anxiety.

2. To assess the level of depression.

3. To develop and administer an interventions with suitable behaviour technology to reduce anxiety and depression.

4. To evaluate the impact of intervention and reducing the anxiety and depression.

\section{LITERATURE REVIEW}

Test anxiety is a major factor contributing to a variety of negative outcomes including psychological distress, academic underachievement, academic failure, and insecurity (Hembree, 1988). Many students have the cognitive ability to do well on exams but may not do so because of high levels of test anxiety. Because of the societal emphasis placed on testing, this could potentially limit their educational and vocational opportunities (Zeidner, 1990). The test anxiety construct is considered as a situation-specific trait accounting for individual differences in the extent to which people find examinations threatening (Spielberger \& Vagg, 1995).

Recent models of test anxiety are process-orientated and emphasise how a great many variables interact in the appraisal of an examination. In Zeidner and Mathews' (2005) self-regulative model short-term distress is seen primarily as the result of negative self-beliefs, maintained by met cognitive strategies (such as heightened attention). Long-term distress is seen as the result of maladaptive person-situation interaction (e.g. negative feedback from others, and avoidance 
which in turn leads to a degradation in skills). The biopsychosocial model (Lowe et al., 2008) proposes that distal (within child/adolescent variables such as intelligence, study skills and academic self-efficacy) combine with proximal (situational or interpersonal) variables to determine the degree of anxiety that is facilitating at low levels, becoming debilitating at higher levels. This estimation is based on a curvilinear relationship between test anxiety and performance, but this relationship is not universally accepted. Some propose that facilitative and debilitating test anxieties are independent, so that a student may be high in one form and low in another (e.g. Putwain, in press).

Research suggests that examinations are stressful for students for four reasons (Denscombe, 2000; Putwain, in press): Consequences; Markers Of Self-Esteem; Judgements From Others; And Fear Appeals By Teachers.

- Consequences: examinations are stressful because of their educational and/or occupational consequences, for example achieving sufficient grades for 'good' particular job.

- Markers of self-esteem: students judge themselves on the basis of their grades, a good grade resulting in high esteem. To a greater or lesser extent there has been an internalisation of the message that esteem can be enhanced through educational achievement.

- Judgements from others: such as parents.

- Fear appeals by teachers: the repeated messages communicated to students over the importance and timing by their teachers were identified as a trigger for the development of stress in some students. Although the fear content of such messages may have been intended as a motivational strategy by teachers, it did not always have the desired effect.

\section{PROPOSED METHODOLOGY}

The proposed methodology includes the following steps:

1. Take a sample of students and divide them into Experimental and Control groups in equal number.

2. Measure and Compare the examination phobia and scholastic score of both the groups.

3. Introduce interventions to the experimental group only.

4. Again measure and compare the examination phobia and scholastic score of both the groups.

5. Introduce interventions to the control group.

6. Again measure and compare the examination phobia and scholastic score of both the groups.

7. Findings are tabulated, analyzed and conclusions are drawn. 


\section{Tools Used:}

The State Anxiety Inventory

Academic score

Personal datasheet

\section{Interventions used:}
A. Cognitive Behavioral Therapy (CBT).
B. Progressive Muscular Relaxation Technique.
C. Benson's Relaxation Response.
D. Guided Imagery.

\section{A. Cognitive Behavioral Therapy}

Cognitive Behavioural Therapy (CBT) can be used to treat people with a wide range of mental health problems. CBT is based on the idea that how we think (cognition), how we feel (emotion) and how we act (behavior) all interacts together.

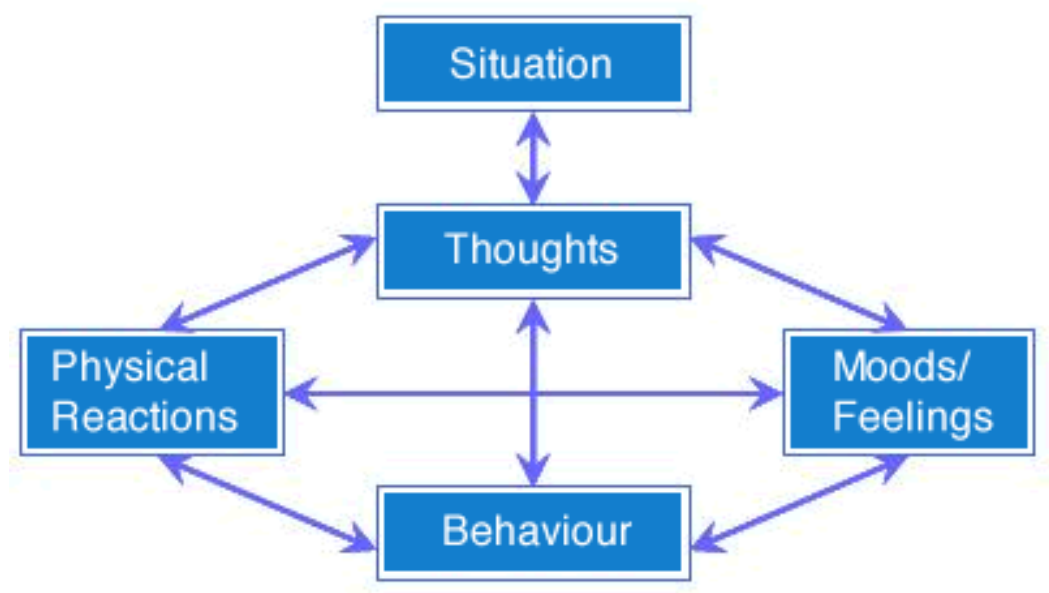

Specifically, our thoughts determine our feelings and our behavior. CBT aims to help people become aware of when they make negative interpretations, and of behavioural patterns which reinforce the distorted thinking. Cognitive Therapy helps people to develop alternative ways of thinking and behaving which reduce the psychological distress. CBT stresses the importance of facing fears on a regular basis. The more you practice, the faster your fears will fade.

\section{B. Progressive Muscular Relaxation Technique.}

Progressive Muscle Relaxation involves systematic tensing and relaxing different muscle groups. However, that the goal of relaxation is not to avoid or eliminate anxiety (because anxiety is not dangerous), but to make it a little easier to ride out these feelings. 


\section{Benson's Relaxation Response.}

The relaxation response is a physical state of deep rest that changes the physical and emotional responses to stress and the opposite of the fight or flight response. It focuses on capacity of mind through becoming silent, to reduce heart rate, breathing and metabolic rate and blood pressure. The procedure is instructed as "Sit in a comfortable posture and then relax your body. Feel your breath and then think of a word, phrase or sound soothing you. The word or sound chosen is not important because it is your choice and liking. Every time you breathe out say your sound silently or mentally. Continue the same for 20 minutes"

\section{Guided Imagery.}

Guided imagery is a method of relaxation which concentrates the mind on positive images in an attempt to reduce pain, stress, etc. In guided imagery, the individual is asked to sit comfortably and guided through imagination of something pleasurable to him such as calm music, beautiful places, etc which brings relaxation. After relaxation the individual is guided through images of his/her mark sheet with desired marks in it.

This technique helps in improved memory, enhanced learning, recover from possible traumas in their life (Physical or Emotional), developing focus and concentration, coping with stress/ anxiety, Reduced test anxiety.

\section{Recommendations to Help Students Overcome Test Anxiety:}

Below are the techniques that can be implemented by school administrators, teachers, school counselors, parents and students themselves to overcome Test Anxiety.

\section{A. School administrators and Teachers:}

- Become aware of students' developmental levels and the pressure they may be placing on students prior to test.

- Teach students successful test-taking strategies that include understanding time limits of tests, the different type of test formats (e.g. Multiple choice, essay, fill in the blank).

- Help students understand test ceilings and provide information on whether or not they will be penalized for incorrect responses. If points are deducted for incorrect responses students should be informed to leave items blank.

- Use school or alarm bell sound which is not like a fire alarm.

- Avoid loud sounds and other distractions while the exam is going on including, reminding the students about the time left for writing exam. Instead of telling them loudly about time left, keep a clock in the exam hall, such that both students and invigilator can see the time duration. Loud sounds can interrupt them from writing exam and it may increase their test anxiety.

- Always teach from known to unknown, so that students will get clear idea about the subject and the topic. Conduct experiments related to the topic being taught and 
connect with the real world applications. This will avoid the fear towards that subject among students.

\section{B. School counsellors}

- Collaborate with school officials to identify students experiencing test anxiety.

- Conduct classroom guidance topics on test anxiety, test-taking strategies, and effective study skills, and consult with teachers.

- Practice different forms of relaxation techniques with students and provide them with the cognitive tools to defeat the negative self-talk they may experience before, during, and after the test.

- Offer workshops to parents focusing on ways they may help their children reduce test anxiety.

- Meet with students experiencing test anxiety individually or in small groups to address this issue in more detail.

- Seek out students who have successfully defeated test anxiety and have them speak or partner with other students to share their experience.

- Be aware of the developmental levels of students and recognize when test anxiety is out of control, because more serious anxiety-related problems could be present

\section{Parents}

- Make sure the children attend school regularly.

- Parents should not scold children after results come. Don't make your child to feel guilty.

- Conducive and happy environment at home will ensure good performance in exams.

- Make sure that the children takes proper rest during regular school days and during the week of tests.

- Evaluate the children's academic progress over a period of time rather than on one single test score.

- Talk with the children and encourage them to do their best.

- Be proactive, contact school officials if they have questions concerning tests results.

- Encourage the children to maintain a healthy diet and exercise on a regular basis.

- Parents must give emotional support and should not thrust their targets on children.

- Don't expect anything from your child now; let him perform to the extent possible.

- Tell your child to be positive and say encouraging words 'you can do'.

- Do not challenge the child.

- Developing expressive feeling.

- Teach them to express their feeling.

- Never compare your child with other children, which will develop low self esteem and low confidence. 


\section{Students are encouraged to:}

- Avoid cramming; develop good study habits and good test taking skills.

- Wear comfortable clothes during the exam and maintain a comfortable and relaxed body posture during the test.

- Be aware of time allotted for the test, read directions carefully, and for time management purposes leave questions blank that they are not sure of and answer them later.

- Do not compare yourself with other students while taking the test.

- Take deep breaths when anxiety levels are high or when negative thoughts are present.

- Get motivated by reading about successful youngsters like the recent CA national topper whose father is an auto driver.

- Always bear in mind that we are studying only to live and not living only to study.

- Accept results with happiness because no one wants to fail. God gives what we deserve.

- Overwhelming anxiety can affect memory and students may forget answers even if they knew.

- Do not discuss about marks at this stage since it will put pressure on students.

- Stay focused: concentrate on your test not others during the examination time. Avoid talking with other students about the subject before an examination.

- Use mnemonics: mnemonics are the techniques of memorization. You can make chart, rhymes or phrase to memorize your lessons.

- Avoid discussion of answers and questions attempted with friends after the examination as it will increase anxiety.

- 'Failures in exams or subjects' is not an indicator of our future life. Never give up.

- During the exam, if you feel that you are going to score less or fail then, sit for 3 hours (Exam duration) and write something relevant to the question or write something relevant to the topic of question or write something related to the lesson or write something related to the subject. Answer all the questions such that just give a chance to the evaluator to give you some marks and pass you'.

- Cognitive Distancing: Try to see your anxious thoughts as guesses not facts. Your mind is trying to protect you by predicting what could happen. Just because it could happen doesn't mean it will. You need to look at objective evidence instead. How likely is it that the negative outcome will actually happen? Is there anything good that might happen instead? What do you think is most likely to happen, based on past experience and other information you have about the situation?

- Practice observing your thoughts, rather than reacting automatically to them. Think of your thoughts as clouds floating by. Look at which draw you in and which make you want to run away. Is there a way you can untangle yourself and just observe your thoughts, rather than reacting? 
- Broadening The View - Are you focusing too narrowly on the threatening aspects of the situation, rather than seeing the whole picture? Anxiety makes our minds contract and focus on the immediate threat without considering the broader context.

- When your mind is stuck in a loop, you can interrupt it by getting up and moving around or doing a different task or activity.

\section{CONCLUSION}

Test anxiety is something that impacts students from all ethnic backgrounds and grade levels. Helping students learn to effectively manage such anxiety is a challenging task that requires a genuine team effort. Students reporting even a small number of depressive symptoms may be at increased risk for academic problems. In order for colleges and universities to decrease the growing number of students battling test anxiety, they must fully understand illness, the causes, and the effects it has on the university and student population.

\section{REFERENCES}

336-353.Gregor, A. (2005). Examination anxiety. School Psychology Int., 26, 617635.Flaxman, P., Bond,

Calvo, M.G. (2007). Anxiety and cognitive performance: Attentional control theory. Emotion, $7(2)$,

Chichester: Wiley.Hembree, R. (1988). Correlates, causes, effects and treatment of test anxiety. Review of Educational Research, 58, 47-77.

Denscombe, M. (2000). Social conditions for stress. British Educational Research Journal, 26(3), 259-374.

Elliot, A.J. \& McGregor, H.A. (1999). Test anxiety and the hierarchical model of approach and avoidance achievement motivation. Journal of Personality and Social Psychology, 76(4), 628-644.

Exam Phobia-Stress Management Among The Students by Parvez, Mohammad; Shakir, Mohd, Educational Quest;Aug2011, Vol. 2 Issue 2, p237

F.W. \& Keogh, E. (2002). Preventing and treating evaluation strain. In F.W. Bond \& W. Dryden (Eds.) Handbook of brief cognitive behavioural therapy.

Hembree, R. (1988). Correlates, causes, effects, and treatment of test anxiety. Review of Educational Research, 58, 7-77.

Lowe, P.A., Lee, S.W., Witteborg, K.M. et al. (2008). The Test Anxiety Inventory for Children and Adolescents (TAICA). Journal of Psychoeducational Assessment, 26(3), 215-230.

McGregor, H.A. (2001). A 2 x 2 achievement goal framework. Journal of Personality and Social Psychology, 80(3), 501-519.Ergene, T. (2003). Effective interventions on test anxiety reduction: A meta analysis. School Psychology International, 24(3), 313-328.Eysenck, M.W., Derakshan, N., Santis, R.

Sarason, I. G. (1988). Anxiety, self-preoccupation, and attention. Anxiety Research, 1, 3-7. 
Sarason, I. G., \& Sarason, B. R. (1990). Test anxiety. In H. Leitenberg (Eds), Handbook of social and evaluative anxiety (pp 475-496). New York: Plenum Press.

Syncamore, J. E., \& Corey, A. L. (1990). Reducing test anxiety. Elementary School Guidance \& Counseling, 24, 231-233.

U. S. Department of Education (1993). Help Your Child Improve in Test-Taking. Washington, DC: U. S. Government Printing Office.

Wilkinson, C. M. (1990). Techniques for overcoming test anxiety. Elementary School Guidance \& Counseling, 24, 234-237.

Zeidner, M. (1990). Does test anxiety bias scholastic aptitude test performance by gender and sociocultural group? Journal of Personality Assessment, 55, 145-160.

Zeidner, M. (1998). Test anxiety: The state of the art. New York: Plenum Press. 